\title{
Pemodelan Pembangkit Listrik Tenaga Angin Kecepatan Tetap Untuk Analisis Aliran Daya
}

\author{
Rudy Gianto* \\ Jurusan Teknik Elektro, Fakultas Teknik, Universitas Tanjungpura \\ "Corresponding author, e-mail: rudygianto@gmail.com
}

\begin{abstract}
Abstrak - Tulisan ini menyajikan metode sederhana dalam memodelkan pembangkit listrik tenaga angin kecepatan tetap untuk analisis aliran daya suatu sistem tenaga listrik. Model yang diusulkan tersebut diturunkan berdasarkan rangkaian ekivalen keadaan-mantap dari generator induksi pembangkit listrik tenaga angin. Teori rangkaian listrik (hukum Kirchhoff dan Ohm) kemudian digunakan untuk mendapatkan model matematis yang dimaksud. Usulan model ini telah berhasil diterapkan pada sistem tenaga listrik 9-bus. Komparasi dengan model lain (model PQ) juga telah dilakukan untuk keperluan validasi. Hasil-hasil pengujian mengkonfirmasi bahwa metode yang diusulkan tersebut adalah akurat.
\end{abstract}

Kata Kunci : Pembangkit listrik tenaga angin, Analisis aliran daya dan Generator induksi

\begin{abstract}
A simple model of fixed-speed wind turbine generating system for load flow analysis of an electrical power system is proposed in this paper. The proposed model is derived based on steady-state equivalent circuit of induction generator of the wind turbine generating system. Electric circuit theory (i.e. Kirchhoff and Ohm laws) is then used to obtain the proposed mathematical model. The proposed model has successfully been applied to 9-bus power system. Comparison with other model (PQ model) has also been carried out for validation purpose. Test results confirm that the proposed method is accurate.
\end{abstract}

Keywords : Wind turbine generating system, Power flow analysis and Induction generator

\section{Pendahuluan}

Beberapatahun belakangan ini integrasi dari pembangkit listrik tenaga angin (PLT angin) pada sistem tenaga telah meningkat secara signifikan. Negara-negara Eropa merupakan negara yang paling banyak mengeksploitasi energi angin ini sebagai sumber energi listrik. Banyak negara Eropa memiliki PLT angin dengan kapasitas terpasang lebih dari $1 \mathrm{GW}$ [1]. Salah satu negara yang memiliki teknologi turbin angin paling maju adalah Denmark. Denmark juga merupakan negara yang potensi energi anginnya terbaik didunia. Saat ini, sekitar $40 \%$ dari kebutuhan listrik Denmark disuplai oleh PLT angin [1].

Indonesia juga memiliki potensi energi angin yang terbilang tidak kecil. Data dari Kementerian ESDM menyebutkan bahwa energi angin di Indonesia berpotensi menghasilkan daya listrik sebesar kurang lebih $60 \mathrm{GW}$ [2]. Oleh karenanya, pemerintah Indonesia telah berkomitmen untuk memaksimalkan pemanfaatan energi terbarukan tersebut. Salah satunya adalah penerbitan peraturan yang dituangkan dalam PP Nomor 79 tahun 2014 mengenai Kebijakan Energi Nasional. Dalam peraturan tersebut disebutkan bahwa target penggunaan energi primer untuk pembangkit listrik pada tahun 2025 adalah dari energi terbarukan (45 GW atau 33\%) dan dari energi tak terbarukan (90 GW atau 67\%). Sedangkan target penggunaan energi angin untuk pembangkit listrik pada tahun 2025 adalah sebesar 1,8 GW [2].

Komitmen pemerintah terhadap pemanfaatan energi terbarukan tersebut sedikit banyak telah membuahkan hasil. Sebagai contoh, saat ini PLT angin dengan kapasitas 75 MW di Sidrap, Sulawesi Selatan telah secara resmi beroperasi [3]. Selain itu, terdapat beberapa proyek PLT angin yang tersebar di beberapa wilayah Indonesia sedang dilakukan pengembangan. Misalnya, PLT angin Jeneponto Tolo 72 MW yang saat ini sudah dalam tahap konstruksi [3]. Sedangkan yang masih dalam tahap rencana 
antara lain berlokasi di Sukabumi di Jawa Barat 170 MW, Lebak dan Pandeglang di Banten (masing-masing $150 \mathrm{MW}$ ), Tanah Laut di Kalimantan Timur 90 MW, Jeneponto 175 MW, Sidrap Phase II 75 MW, Sidrap Phase III 200 MW, dan Timor Tengah Selatan 20 MW serta Bantul 50 MW [3].

Analisis aliran daya merupakan alat yang biasa digunakan untuk mengevaluasi operasi keadaan-mantap (steady-state) suatu sistem tenaga listrik [4]. Analisis aliran daya dapat didefinisikan sebagai perhitungan tegangantegangan bus sistem pada kondisi beban dan pembangkitan tertentu. Setelah tegangantegangan bus ini dihitung, selanjutnya besarnya pembangkitan daya, aliran daya dan rugi-rugi daya pada saluran transmisi akan dapat dihitung. Pada analisis aliran daya, bus-bus yang ada pada sistem dikelompokkan kedalam tiga jenis yaitu: bus referensi (Slack), pembangkit (PV) dan beban (PQ). Pengelompokan ini dimaksudkan agar masalah aliran daya tersebut dapat dicari solusinya.

Bus-bus pembangkit konvensional yang menggunakan generator sinkron dapat dimodelkan sebagai bus PV. Namun demikian, untuk bus-bus pembangkit dengan PLT angin yang konverter energi listriknya biasanya berupa generator asinkron (generator induksi), model bus PV tersebut tidak lagi valid untuk digunakan. Hal ini disebabkan karena umumnya pembangkit-pembangkit listrik tipe ini tidak memiliki kemampuan untuk mengendalikan output daya aktif dan besar tegangan. Oleh sebab itu, pengembangan model dari PLT angin diperlukan agar analisis aliran daya dari sistem tersebut dapat dilakukan dan kondisi operasinya bisa dievaluasi.

Beberapa peneliti telah melakukan kajian tentang pemodelan PLT angin untuk analisis aliran daya, dimana beberapa diantaranya adalah seperti yang dilaporkan pada [5-14]. Pada [5-11], suatu model matematik dari PLT angin telah dikembangkan dimana kemudian persamaan matematik ini (bersama-sama dengan persamaan aliran daya yang telah ada) diselesaikan secara iteratif. Namun demikian, rumusan model matematis yang diusulkan tersebut cukup rumit. Sedangkan [12-14] mengusulkan suatu metode untuk mengikut-sertakan model PLT angin kedalam program aliran daya. Model PLT angin yang diusulkan tersebut menambah dua bus (simpul), dua elemen seri, satu elemen shunt dan satu beban pada jaringan sistem tenaga yang ada. Hal ini mengakibatkan ukuran sistem menjadi bertambah besar dan jumlah persamaan yang harus diselesaikan juga semakin banyak.

Tulisan ini mengusulkan metode sederhana untuk memodelkan dan mengikut-sertakan PLT angin pada analisis aliran daya. Model yang diusulkan tersebut diturunkan berdasarkan rangkaian-T ekivalen dari mesin asinkron yang digunakan pada PLT angin. Pembentukan model dilakukan dengan bantuan teori rangkaian listrik dimana hukum-hukum Kirchhoff dan Ohm digunakan dalam pembentukannya. Model yang diusulkan ini juga dapat dengan mudah diikutsertakan pada analisis aliran daya suatu sistem tenaga listrik.

\section{Perumusan Masalah Aliran Daya}

Seperti yang telah diuraikan, analisis aliran daya dimaksudkan untuk mengetahui nilai-nilai dari besaran listrik seperti: tegangan bus (simpul), daya yang dibangkitkan oleh generator, aliran dan rugi-rugi daya pada saluran transmisi.

Solusi dari masalah aliran daya dapat diperoleh dengan menyelesaikan secara simultan persamaan-persamaan nonlinier berikut:

$$
\begin{aligned}
& S_{G i}-S_{L i}-V_{i} \sum_{j=1}^{n} Y_{i j}^{*} V_{j}^{*}=0 \\
& i=1,2, \ldots, n
\end{aligned}
$$

dimana:

$S_{G i}=P_{G i}+j Q_{G i}:$ pembangkitan daya pada bus-i

$S_{L i}=P_{L i}+j Q_{L i}$ : pembebanan daya pada bus-i

$V_{i}=\left|V_{i}\right|\left\llcorner\delta_{i} \quad\right.$ : tegangan pada bus-i

$Y_{i j}=\left|Y_{i j}\right|\left\llcorner\theta_{i j}\right.$ : elemen-ij dari matriks admitansi

$n \quad$ : jumlah bus

Pada (1), nilai-nilai untuk $S_{L i}$ biasanya diketahui karena analisis aliran daya umumnya dilakukan pada kondisi beban tertentu. Sedangkan nilai-nilai untuk $Y_{i j}$ ditentukan dari matriks admitansi yang dihitung berdasarkan data jaringan sistem tenaga. Dengan demikian, terlihat bahwa setiap bus pada sistem tenaga akan dikarakterisasi melalui empat besaran yaitu: $P_{G}, Q_{G},|V|$ dan $\delta$. Sedangkan jumlah persamaan yang ada untuk setiap bus adalah dua persamaan 
yang diperoleh dengan cara memisahkan bagian riil dan imajiner dari (1).

Agar supaya (1) dapat dicari solusinya, maka dua dari empat besaran pada setiap bus tersebut harus ditentukan atau dispesifikasi nilainya. Hal ini dapat dilakukan dengan mendefinisikan tiga tipe bus seperti yang diperlihatkan pada Tabel 1 . Perlu dicatat bahwa karena bus beban tidak mengandung pembangkit, maka pembangkitan daya pada bus tersebut adalah nol $\left(P_{G}=Q_{G}=0\right)$.

Pendefinisian tersebut mengakibatkan jumlah besaran yang akan dicari atau dihitung pada setiap bus akan menjadi sama dengan jumlah persamaan nonlinier yang ada atau yang akan diselesaikan. Hal ini berimplikasi bahwa (1) dapat dicari penyelesaiannya, sehingga analisis aliran daya menjadi mungkin untuk dilakukan, dan kondisi operasi keadaan mantap (steadystate) sistem bisa dievaluasi.

Tabel 1. Tipe Bus dan Besaran Listrik

\begin{tabular}{|c|c|c|c|}
\hline No & Tipe Bus & $\begin{array}{c}\text { Besaran Yang } \\
\text { Dispesifikasi }\end{array}$ & $\begin{array}{c}\text { Besaran } \\
\text { Yang Dicari }\end{array}$ \\
\hline 1 & $\begin{array}{c}\text { Referensi } \\
\text { (Slack) }\end{array}$ & $|V|$ dan $\delta$ & $P_{G}$ dan $Q_{G}$ \\
\hline 2 & $\begin{array}{c}\text { Beban } \\
(\mathrm{PQ})\end{array}$ & $P_{G}=Q_{G}=0$ & $|V|$ dan $\delta$ \\
\hline 3 & $\begin{array}{l}\text { Pembangkit } \\
\text { (PV) }\end{array}$ & $P_{G}$ dan $|V|$ & $Q_{G}$ dan $\delta$ \\
\hline
\end{tabular}

\section{Pemodelan PLT Angin}

Seperti yang telah dibahas sebelumnya, busbus pembangkit dengan PLT angin tidak dapat dimodelkan sebagai bus PV karena pembangkit listrik tipe ini umumnya tidak memiliki kemampuan untuk mengendalikan output daya aktif dan besar tegangan. Oleh sebab itu, agar analisis aliran daya dari sistem yang mengandung PLT angin dapat dilakukan, model dari PLT angin tersebut perlu dibentuk terlebih dahulu. Hal ini akan dibahas secara lebih detil sebagai berikut.

PLT angin dengan generator induksi rotorsangkar (GIRS) yang terkoneksi pada suatu sistem tenaga listrik ditunjukkan pada Gambar 1a. Pada Gambar 1b, $P_{m}$ merupakan masukan daya mekanik yang berasal dari turbin angin untuk GIRS, sedangkan $S_{g}$ adalah keluaran daya listrik dari GIRS. Masukan daya mekanik ini biasanya diketahui nilainya karena pabrik pembuat turbin umumnya menyediakan nilai- nilai untuk $P_{m}$ sebagai fungsi dari kecepatan angin.

Gambar 2 memperlihatkan rangkaian pengganti dari GIRS, dimana $R_{1}, X_{1}, R_{2}, X_{2}, R_{c}$ dan $X_{m}$ berturut-turut menyatakan resistansi stator, reaktansi bocor stator, resistansi rotor, reaktansi bocor rotor, resistansi rugi-rugi inti dan reaktansi magnetik. Sedangkan $R_{2}(1-s) / s$ adalah resistansi dinamik, dimana daya yang diserap oleh resistansi ini menggambarkan masukan daya mekanik untuk GIRS.
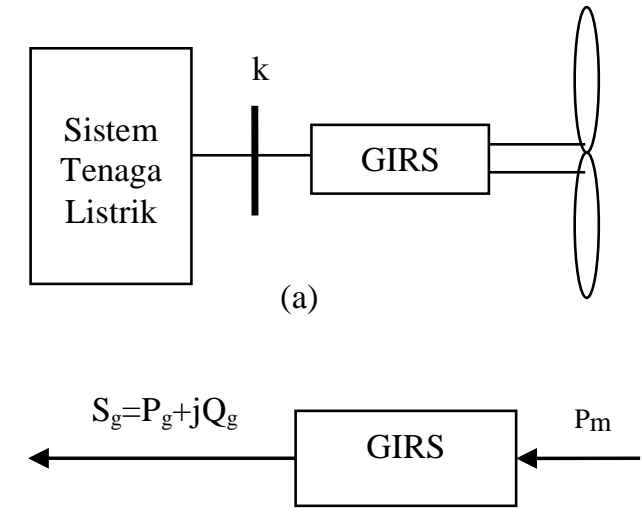

(b)

Gambar 1. PLT angin terhubung pada sistem

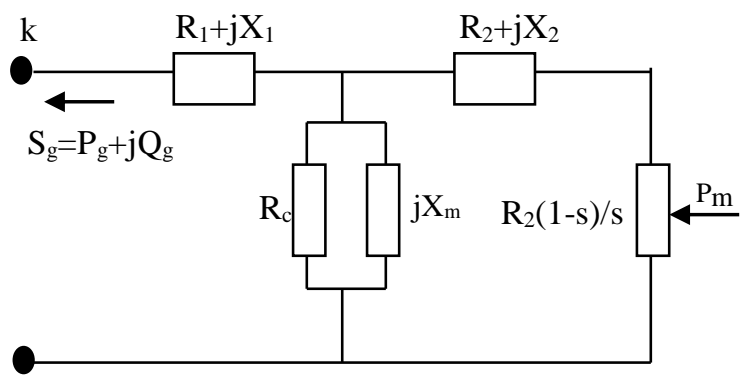

Gambar 2. Rangkaian pengganti dari GIRS

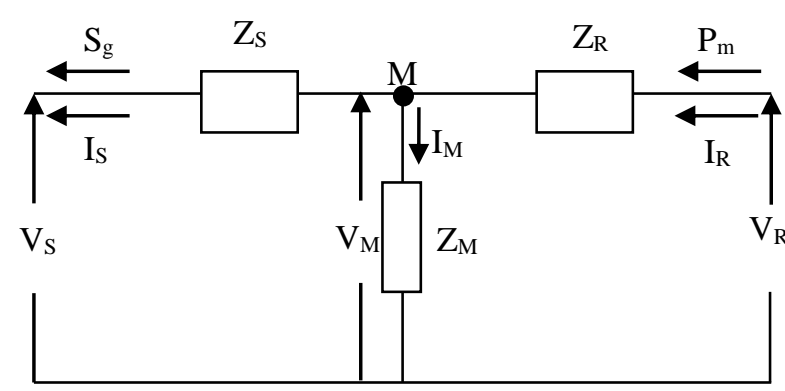

Gambar 3. Rangkaian pengganti dari GIRS dalam bentuk impedansi 
Gambar 3 juga merupakan rangkaian pengganti dari GIRS. Akan tetapi, pada Gambar 3, parameter-parameter dari GIRS dinyatakan dalam bentuk impedansi. Impedansi-impedansi $Z_{S}, Z_{R}$ dan $Z_{M}$ pada Gambar 3 tersebut diberikan oleh:

$$
\begin{aligned}
& Z_{S}=R_{1}+j X_{1} \\
& Z_{R}=R_{2}+j X_{2} \\
& Z_{M}=j R_{c} X_{m} /\left(R_{c}+j X_{m}\right)
\end{aligned}
$$

Dengan melihat Gambar 3, dan berdasarkan teori rangkaian listrik (hukum-hukum Kirchhoff dan $\mathrm{Ohm}$ ), dapat ditunjukkan bahwa arus-arus stator dan rotor berturut-turut adalah (penurunannya dapat dilihat pada Lampiran):

$$
\begin{aligned}
& I_{S}=\frac{Z_{M}}{Z_{S}+Z_{M}} I_{R}-\frac{1}{Z_{S}+Z_{M}} V_{S} \\
& I_{R}=\frac{1}{Z_{R}} V_{R}-\frac{1}{Z_{R}} V_{S}-\frac{Z_{S}}{Z_{R}} I_{S}
\end{aligned}
$$

dimana $V_{S}$ adalah tegangan stator dari GIRS yang juga merupakan tegangan pada bus PLT angin. Sedangkan $V_{R}=\left|V_{R}\right|\llcorner\alpha$ adalah tegangan rotor dari GIRS.

Sedangkan keluaran daya listrik dan masukan daya mekanik dari GIRS dapat dihitung melalui persamaan-persamaan berikut:

$$
\begin{aligned}
& S_{g}=P_{g}+j Q_{g}=V_{S} I_{S} * \\
& S_{m}=P_{m}+j 0=V_{R} I_{R} *
\end{aligned}
$$

Berdasarkan (5) dan (6), arus stator sebagai fungsi keluaran daya listrik dan tegangan stator, serta arus rotor sebagai fungsi masukan daya mekanik dan tegangan rotor dapat dirumuskan sebagai:

$$
\begin{gathered}
I_{S}=\frac{S_{g} *}{V_{S} *} \\
I_{R}=\frac{P_{m}}{V_{R} *}
\end{gathered}
$$

Substitusi (7) dan (8) pada (3) dan (4), serta mengatur kembali hasilnya, akan diperoleh:

$$
\begin{aligned}
& \frac{S_{g} *}{V_{S} *}-\frac{Z_{M}}{Z_{S}+Z_{M}} \frac{P_{m}}{V_{R} *}+\frac{1}{Z_{S}+Z_{M}} V_{S}=0 \\
& \frac{P_{m}}{V_{R} *}-\frac{1}{Z_{R}} V_{R}+\frac{1}{Z_{R}} V_{S}+\frac{Z_{S}}{Z_{R}} \frac{S_{g} *}{V_{S}^{*}}=0
\end{aligned}
$$

Persamaan (9) dan (10) merupakan usulan model matematis dari PLT angin untuk diintegrasikan pada analisis aliran daya suatu sistem tenaga listrik. Dengan demikian, untuk mendapatkan solusi masalah aliran daya dari sistem yang mengandung PLT angin, selain (1), persamaan tambahan yang harus diselesaikan adalah (9) dan (10). Sedangkan variabel tambahan yang harus dihitung adalah $S_{g}$ dan $V_{R}$ (lihat Tabel 2). Perlu dicatat bahwa pada Tabel 2, pembangkitan daya $P_{G}$ dan $Q_{G}$ untuk bus PLT angin adalah nol karena bus tersebut tidak mengandung pembangkit konvesional.

Tabel 2. Tipe Bus dan Besaran Listrik untuk Sistem dengan PLT Angin

\begin{tabular}{|c|c|c|c|}
\hline No & Tipe Bus & $\begin{array}{c}\text { Besaran Yang } \\
\text { Dispesifikasi }\end{array}$ & $\begin{array}{c}\text { Besaran Yang } \\
\text { Dicari }\end{array}$ \\
\hline 1 & $\begin{array}{c}\text { Referensi } \\
\text { (Slack) }\end{array}$ & $|V|$ dan $\delta$ & $P_{G}$ dan $Q_{G}$ \\
2 & $\begin{array}{c}\text { Beban } \\
\text { (PQ) }\end{array}$ & $P_{G}=Q_{G}=0$ & $|V|$ dan $\delta$ \\
3 & $\begin{array}{c}\text { Pembangkit } \\
\text { (PV) }\end{array}$ & $P_{G}$ dan $|V|$ & $Q_{G}$ dan $\delta$ \\
4 & PLT Angin & $P_{G}=Q_{G}=0$ & $\begin{array}{c}P_{g}, Q_{g},|V|, \delta, \\
\left|V_{R}\right|, \text { dan } \alpha\end{array}$ \\
\hline
\end{tabular}

\section{Metode Solusi Masalah Aliran Daya}

Dari uraian pada Bab 2 dan 3 terlihat bahwa rumusan dari masalah aliran daya adalah berbentuk persamaan-persamaan nonlinier. Penyelesaian terhadap set persamaan nonlinier tersebut biasanya dilakukan melalui teknik iteratif. Pada teknik ini, langkah pertama dalam proses perhitungan adalah memperkirakan atau mengestimasi nilai awal dari besaran-besaran yang akan dicari solusinya. Melalui suatu faktor koreksi, estimasi awal ini kemudian diperbaiki secara berulang-ulang (iteratif) sampai diperoleh solusi dengan akurasi yang diinginkan. 
Faktor koreksi pada penyelesaian set persamaan nonlinier dapat dihitung dengan menggunakan cara langsung (seperti pada metode Newton-Raphson). Atau, faktor koreksi ini juga dapat dihitung melalui teknik optimisasi (seperti pada metode trust-region) [4].

\section{Hasil dan Pembahasan}

\subsection{Sistem Test}

Usulan model untuk PLT angin seperti yang dibahas di Bab 3 akan diverifikasi dengan menggunakan sistem pada Gambar 4. Sistem ini didasarkan pada sistem 9 bus [15], yang kemudian dimodifikasi dengan menambahkan PLT angin yang terhubung pada bus N8 melalui transformator. Data sistem, termasuk data GIRS dari PLT angin, diperlihatkan pada Tabel 3, 4 dan 5. Semua data dalam pu pada dasar 100 MVA. Perlu juga ditambahkan disini bahwa seluruh perhitungan pada tulisan ini dilakukan pada komputer pribadi (PC) dengan bantuan perangkat lunak MATLAB ${ }^{\mathrm{TM}}$.

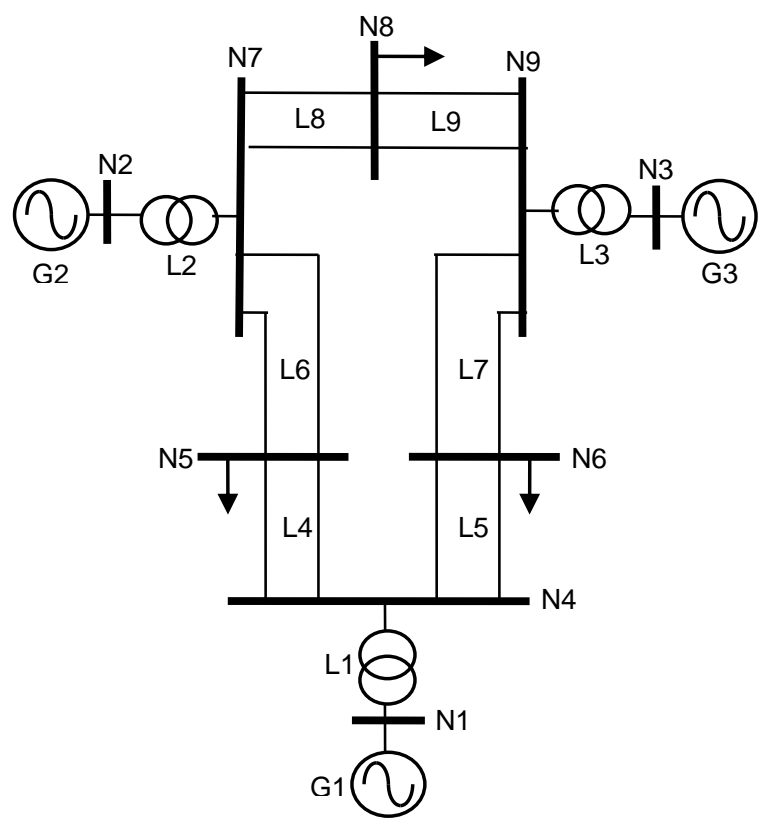

Gambar 4. Sistem 3-mesin 9-bus
Tabel 3. Data Cabang (Saluran)

\begin{tabular}{|c|c|c|c|}
\hline Sal. & $\begin{array}{c}\text { Bus } \\
\mathrm{p}-\mathrm{q}\end{array}$ & $\begin{array}{c}\text { Impedansi Seri } \\
(\mathrm{Z})\end{array}$ & $\begin{array}{c}\text { Admitansi Shunt } \\
(\text { Ysh/2) }\end{array}$ \\
\hline 1 & $1-4$ & $\mathrm{j} 0,1184$ & 0 \\
2 & $2-7$ & $\mathrm{j} 0,1823$ & 0 \\
3 & $3-9$ & $\mathrm{j} 0,2399$ & 0 \\
4 & $4-5$ & $0,0100+\mathrm{j} 0,0850$ & $\mathrm{j} 0,0880$ \\
5 & $4-6$ & $0,0170+\mathrm{j} 0,0920$ & $\mathrm{j} 0,0790$ \\
6 & $5-7$ & $0,0320+\mathrm{j} 0,1610$ & $\mathrm{j} 0,1530$ \\
7 & $6-9$ & $0,0390+\mathrm{j} 0,1700$ & $\mathrm{j} 0,1790$ \\
8 & $7-8$ & $0,0085+\mathrm{j} 0,0720$ & $\mathrm{j} 0,0745$ \\
9 & $8-9$ & $0,0119+\mathrm{j} 0,1008$ & $\mathrm{j} 0,1045$ \\
10 & $8-10$ & $\mathrm{j} 0,1000$ & 0 \\
\hline
\end{tabular}

Tabel 4. Data Bus (Simpul)

\begin{tabular}{|c|c|c|c|c|c|}
\hline Bus & $|\mathrm{V}|$ & $\delta$ & $\begin{array}{c}\text { Pembang } \\
\text { kitan }\end{array}$ & Beban & Tipe \\
\hline 1 & 1,04 & 0 & - & 0 & Slack \\
2 & 1,02 & - & $1,50+\mathrm{j}-$ & 0 & $\mathrm{PV}$ \\
3 & 1,01 & - & $1,00+\mathrm{j}-$ & 0 & $\mathrm{PV}$ \\
4 & - & - & 0 & 0 & $\mathrm{PQ}$ \\
5 & - & - & 0 & $1,25+\mathrm{j} 0,50$ & $\mathrm{PQ}$ \\
6 & - & - & 0 & $0,90+\mathrm{j} 0,30$ & $\mathrm{PQ}$ \\
7 & - & - & 0 & 0 & $\mathrm{PQ}$ \\
8 & - & - & 0 & $1,00+\mathrm{j} 0,35$ & $\mathrm{PQ}$ \\
9 & - & - & 0 & 0 & $\mathrm{PQ}$ \\
10 & - & - & - & 0 & $\mathrm{PLT}$ \\
& & & 0 & $\mathrm{~B}$ \\
\hline
\end{tabular}

Keterangan: - = besaran yang akan dicari

Tabel 5. Data PLT Angin

\begin{tabular}{|c|c|}
\hline Komponen & Parameter \\
\hline GIRS & $\begin{array}{c}\text { Stator: } \mathrm{R}_{1}=0,020 ; \mathrm{X}_{1}=0,100 \\
\text { Rotor: } \mathrm{R}_{2}=0,018 ; \mathrm{X}_{1}=0,180 \\
\text { Inti Magnetik: } \mathrm{R}_{\mathrm{c}}=50 ; \mathrm{X}_{\mathrm{m}}=3,2\end{array}$ \\
\hline Transformator & Impedansi: $\mathrm{Z}_{\mathrm{T}}=\mathrm{j} 0,1$ \\
\hline $\begin{array}{c}\text { Kapasitor } \\
\text { Shunt }\end{array}$ & Kapasitas: $\mathrm{Q}_{\mathrm{CAP}}=0,3$ \\
\hline
\end{tabular}

\subsection{Hasil dan Pembahasan}

Hasil-hasil dari perhitungan aliran daya ditunjukkan pada Tabel 6 dan 7. Tabel 6 memperlihatkan hasil perhitungan besar tegangan $(|V|)$ pada bus PLT angin (bus 10), sedangkan Tabel 7 memperlihatkan hasil perhitungan output daya listrik PLT angin $\left(P_{g}+j Q_{g}\right)$. Perhitungan-perhitungan tersebut dilakukan pada berbagai nilai input daya mekanik $P_{m}$ yaitu mulai $0,1 \mathrm{~s} / \mathrm{d} 1,0 \mathrm{pu}$. Nilainilai input daya mekanik yang bervariasi ini 
menggambarkan kondisi kecepatan angin rendah sampai tinggi.

Sebagai pembanding, hasil perhitungan dari metode lain juga diperlihatkan pada Tabel 6 dan 7. Metode yang digunakan sebagai pembanding pada tulisan ini adalah metode yang relatif baru yaitu model PQ [10, 11]. Dari tabel-tabel tersebut terlihat bahwa model PLT angin yang diusulkan adalah akurat dan sangat bersesuaian dengan hasil dari model PQ tersebut.

Hasil-hasil perbandingan tersebut diatas memperlihatkan bahwa model PLT angin yang diusulkan adalah valid, dan oleh karenanya dapat digunakan untuk mengintegrasikan PLT angin pada analisis aliran daya suatu sistem tenaga listrik.

Tabel 6. Besar Tegangan Pada Bus PLT Angin

\begin{tabular}{|c|c|c|}
\hline Pm & $\begin{array}{c}\text { Model Yang } \\
\text { Diusulkan }\end{array}$ & Model PQ [10, 11] \\
\hline 0,1 & 0,9907 & 0,9907 \\
0,2 & 0,9887 & 0,9887 \\
0,3 & 0,9847 & 0,9847 \\
0,4 & 0,9785 & 0,9785 \\
0,5 & 0,9701 & 0,9701 \\
0,6 & 0,9588 & 0,9588 \\
0,7 & 0,9440 & 0,9440 \\
0,8 & 0,9244 & 0,9244 \\
0,9 & 0,8969 & 0,8969 \\
1,0 & 0,8502 & 0,8502 \\
\hline
\end{tabular}

Ket: besar tegangan adalah dalam pu

Tabel 7. Output Daya Listrik PLT Angin

\begin{tabular}{|c|c|c|}
\hline Pm & $\begin{array}{c}\text { Model Yang } \\
\text { Diusulkan }\end{array}$ & Model PQ [10, 11] \\
\hline 0,1 & $0,0793-\mathrm{j} 0,3010$ & $0,0793-\mathrm{j} 0,3010$ \\
0,2 & $0,1781-\mathrm{j} 0,3096$ & $0,1781-\mathrm{j} 0,3096$ \\
0,3 & $0,2762-\mathrm{j} 0,3230$ & $0,2762-\mathrm{j} 0,3230$ \\
0,4 & $0,3734-\mathrm{j} 0,3416$ & $0,3734-\mathrm{j} 0,3416$ \\
0,5 & $0,4697-\mathrm{j} 0,3660$ & $0,4697-\mathrm{j} 0,3660$ \\
0,6 & $0,5649-\mathrm{j} 0,3937$ & $0,5649-\mathrm{j} 0,3937$ \\
0,7 & $0,6588-\mathrm{j} 0,4363$ & $0,6588-\mathrm{j} 0,4363$ \\
0,8 & $0,7509-\mathrm{j} 0,4868$ & $0,7509-\mathrm{j} 0,4868$ \\
0,9 & $0,8402-\mathrm{j} 0,5553$ & $0,8402-\mathrm{j} 0,5553$ \\
1,0 & $0,9226-\mathrm{j} 0,6671$ & $0,9226-\mathrm{j} 0,6671$ \\
\hline
\end{tabular}

Ket: output daya listrik adalah dalam pu

Perlu juga ditambahkan disini bahwa instalasi kapasitor shunt pada terminal PLT angin diperlukan untuk membantu catu daya reaktif yang dibutuhkan oleh generator induksi dari PLT angin tersebut. Tabel 6 dan 7 diatas memperlihatkan hasil-hasil perhitungan untuk kapasitor shunt sebesar 0,3 pu. Pada tulisan ini juga akan diselidiki pengaruhnya terhadap penampilan sistem bila kapasitor yang terpasang tersebut memiliki kapasitas yang lebih besar. Tabel 8 memperlihatkan hasil perihtungan besar tegangan dan daya yang dibangkitkan PLT angin untuk kapasitor shunt dengan kapasitas 0,5 pu.

Untuk mengamati pengaruh dari pemasangan kapasitor tersebut secara lebih detil, hasil-hasil perhitungan diatas (Tabel 6-8) juga disajikan dalam bentuk grafik (lihat Gambar $5-7$ ). Gambar 5 merupakan plot dari input daya mekanik $\left(P_{m}\right)$ terhadap tegangan terminal PLT angin $(|V|)$. Gambar 6 memperlihatkan plot dari input daya mekanik $\left(P_{m}\right)$ terhadap output dayaaktif PLT angin $\left(P_{g}\right)$. Sedangkan Gambar 7 memperlihatkan plot dari input daya mekanik $\left(P_{m}\right)$ terhadap negatif dari output daya-reaktif PLT angin $\left(-Q_{g}\right)$.

Tabel 8. Tegangan dan Output Daya Listrik PLT Angin Untuk Kapasitor Shunt Sebesar 0,5 pu

\begin{tabular}{|c|c|c|}
\hline Pm & Besar Tegangan & Output Daya Listrik \\
\hline 0,1 & 1,0316 & $0,0776-\mathrm{j} 0,3259$ \\
0,2 & 1,0300 & $0,1765-\mathrm{j} 0,3339$ \\
0,3 & 1,0266 & $0,2747-\mathrm{j} 0,3464$ \\
0,4 & 1,0214 & $0,3722-\mathrm{j} 0,3636$ \\
0,5 & 1,0143 & $0,4688-\mathrm{j} 0,3860$ \\
0,6 & 1,0050 & $0,5645-\mathrm{j} 0,4141$ \\
0,7 & 0,9931 & $0,6591-\mathrm{j} 0,4490$ \\
0,8 & 0,9778 & $0,7524-\mathrm{j} 0,4924$ \\
0,9 & 0,9579 & $0,8438-\mathrm{j} 0,5475$ \\
1,0 & 0,9305 & $0,9323-\mathrm{j} 0,6214$ \\
\hline
\end{tabular}

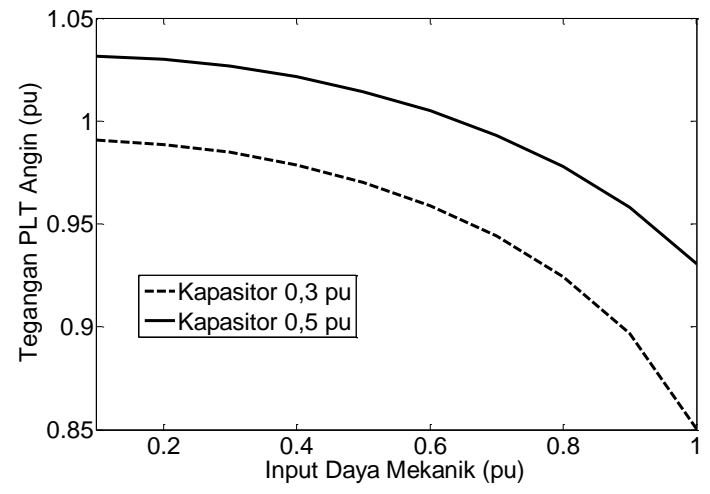

Gambar 5. Variasi tegangan PLT angin 


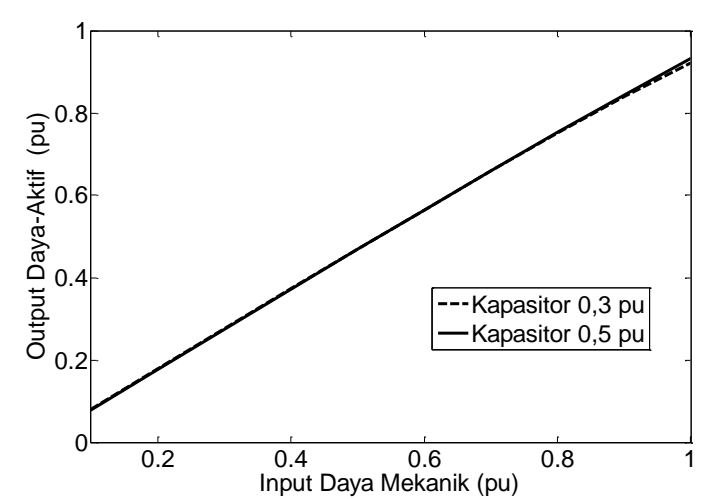

Gambar 6. Variasi daya-aktif PLT angin

Gambar 5 jelas memperlihatkan bahwa kapasitor shunt dapat mendukung kebutuhan daya reaktif dari PLT angin. Hal ini terlihat dengan membaiknya profil tegangan untuk kapasitas kapasitor yang lebih besar. Walaupun nilainya sedikit lebih kecil dari masukan daya mekanik, daya aktif yang dibangkitkan oleh PLT angin selalu proporsional dengan masukan daya mekanik (lihat Gambar 6).

Namun, tidak demikian halnya untuk kasus variasi daya reaktif dari PLT angin. Dengan meningkatnya masukan daya mekanik, peningkatan daya reaktif dari PLT angin tidak terjadi secara proporsional akan tetapi terjadi secara hampir eksponensial (lihat Gambar 7). Dengan kata lain, meningkatnya keluaran daya aktif dari PLT angin akan membutuhkan suplai daya reaktif yang lebih besar.

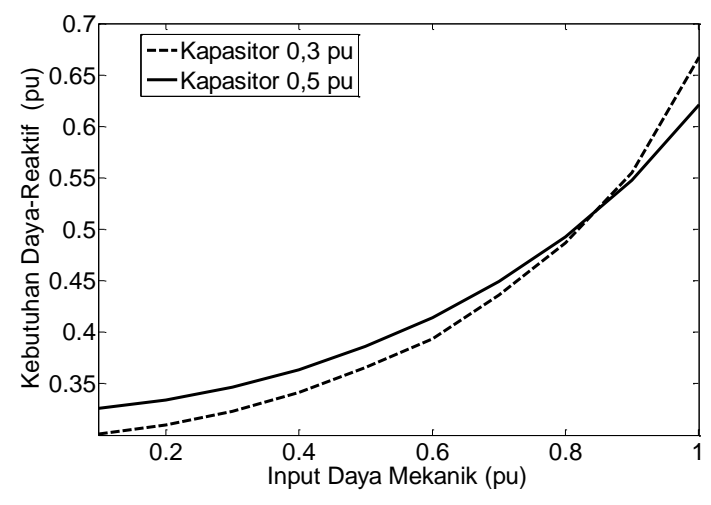

Gambar 7. Variasi daya-reaktif PLT angin

\section{Kesimpulan}

Metode sederhana untuk memodelkan dan mengintegrasikan PLT angin pada analisis aliran daya sistem tenaga listrik telah diusulkan dan dibahas pada tulisan ini. Model yang diusulkan tersebut diturunkan berdasarkan rangkaian ekivalen keadaan-mantap dari generator induksi yang digunakan oleh PLT angin tersebut. Model matematik ini kemudian diikut-sertakan pada analisis aliran daya agar operasi keadaan-mantap sistem secara keseluruhan (termasuk PLT angin) dapat dievaluasi. Hasil-hasil pengujian mengkonfirmasi bahwa model PLT angin yang diusulkan adalah valid, dan oleh karenanya dapat digunakan sebagai cara untuk mengintegrasikan PLT angin pada analisis aliran daya suatu sistem tenaga listrik.

\section{Daftar Pustaka}

[1] Pineda, I., dkk, "Wind in Power 2017: Annual Combined Onshore and Offshore Wind Energy Statistics", WindEurope Report, Brussels, Feb. 2018.

[2] Hutapea, M., "Potensi Bisnis Energi Baru Terbarukan", Kementerian Energi dan Sumber Daya Mineral, Jakarta, Okt. 2017.

[3] Potensi Pengembangan Listrik Tenaga Angin Indonesia.

https://www.esdm.go.id/id/mediacenter/arsip-berita/potensi-pengembanganlistrik-tenaga-angin-indonesia-berikutsebaran-lokasinya (diakses tanggal 14 Februari 2019).

[4] Gianto, R., dan Khwee, K.H., "Solusi Aliran Daya untuk Sistem Distribusi Tak Seimbang dengan Menggunakan Metode TrustRegion", Jurnal Nasional Teknik Elektro, vol. 5, no. 1, pp. 13-20, 2016.

[5] Divya, K.C., dan Nagendra Rao, P.S.,"Models for Wind Turbine Generating Systems and Their Applications in Load Flow Studies", Electric Power Systems Research, vol. 76, pp. 844-856, 2006.

[6] Zhao, M., Chen, Z., dan Blaaberg, F.,"Load Flow Analysis for Variable Speed Offshore Wind Farms", IET Renew. Power Gener., vol. 3, no. 2, pp. 120-132, 2009.

[7] Eminoglu, U., Dursun, B., dan Hocaoglu, M.H.,"Incorporation of New Wind Turbine Generating System Model into Distribution 
Systems Load Flow Analysis", Wind Energy, vol. 12, pp. 375-390, 2009.

[8] Castro, L.M., et al.,"A Unified Approach for the Solution of Power Flows in Electric Power Systems Including Wind Farms", Electric Power Systems Research, vol. 81, pp. 1859-1865, 2011.

[9] Feijoo, A., Pazos, J.L dan Villanueva, D.,"Conventional Asynchronous Wind Turbine Models - Mathematical Expressions for the Load Flow Analysis", International Journal of Energy Engineering (IJEE), Dec. vol. 3, no. 6, pp. 269-278, 2013.

[10] Feijoo, A. dan Villanueva, D.,“A PQ Model for Asynchronous Machines Based on Rotor Voltage Calculation”, IEEE Trans. Energy Conversion, vol. 2, pp. 813-814, 2016.

[11] Feijoo, A. dan Villanueva, D.,"Correction to "A PQ Model for Asynchronous Machines Based on Rotor Voltage Calculation", IEEE Trans. Energy Conversion, vol. 31 , no. 3 , pp. 1228-1228, 2016.

[12] Haque, M.H.,"Evaluation of Power Flow Solutions with Fixed Speed Wind Turbine Generating Systems", Energy Conversion and Management, vol. 79, pp. 511-518, 2014.

[13] Wang, J., Huang, C. dan Zobaa, A.F.,"Multiple-Node Models of Asynchronous Wind Turbines in Wind Farms for Load Flow Analysis", Electric Power Components and Systems, vol. 44, no. 2, pp. 135-141, 2015.

[14] Haque, M.H.,"Incorporation of Fixed Speed Wind Turbine Generators in Load Flow Analysis of Distribution Systems", International Journal of Renewable Energy Technology, vol. 6, no. 4, pp. 317-324, 2015.

[15] Anderson, P.M. dan Fouad, A.A., "Power System Control and Stability", Wiley-IEEE Press, New Jersey, 2003.

\section{Lampiran}

\section{L.1. Penurunan Rumus Arus Stator}

Penerapan hukum Kirchhoff untuk arus pada simpul $M$ dari rangkaian pada Gambar 3 menghasilkan:

$$
I_{S}-I_{R}+I_{M}=0
$$

Dengan menggunakan hukum Ohm, arus yang mengalir pada rangkaian inti magnetik GIRS adalah:

$$
I_{M}=\frac{V_{M}}{Z_{M}}=\frac{V_{S}+Z_{S} I_{S}}{Z_{M}}
$$

Substitusi (L.2) pada (L.1) dan mengatur kembali hasilnya akan menghasilkan:

$$
\frac{Z_{M}+Z_{S}}{Z_{M}} I_{S}-I_{R}+\frac{1}{Z_{M}} V_{S}=0
$$

Berdasarkan (L.3), arus stator GIRS dapat dirumuskan sebagai:

$$
I_{S}=\frac{Z_{M}}{Z_{M}+Z_{S}} I_{R}-\frac{1}{Z_{M}+Z_{S}} V_{S}
$$

\section{L.2. Penurunan Rumus Arus Rotor}

Dengan menggunakan hukum Kirchhoff untuk tegangan pada rangkaian Gambar 3 akan diperoleh:

$$
V_{R}-V_{S}=Z_{S} I_{S}+Z_{R} I_{R}
$$

Berdasarkan (L.5), rumusan dari arus rotor GIRS akan berbentuk:

$$
I_{R}=\frac{1}{Z_{R}} V_{R}-\frac{1}{Z_{R}} V_{S}-\frac{Z_{S}}{Z_{R}} I_{S}
$$

\section{Biodata Penulis}

Rudy Gianto, mendapatkan gelar S1, S2 dan S3 berturut-turut dari Universitas Tanjungpura tahun 1991, Institut Teknologi Bandung tahun 1995 dan University of Western Australia tahun 2008. Saat ini penulis terdaftar sebagai dosen Teknik Elektro Universitas Tanjungpura Pontianak. 